\title{
A Survey on Clinical Practicums in Graduate School Departments of Communication Disorders
}

\author{
Hwa Young Pyo \\ Department of Speech-Language Pathology, College of Health Science, Chosun University, Gwangju, Korea
}

Correspondence: Hwa Young Pyo, PhD Department of Speech-Language Pathology, College of Health Science, Chosun University, 309 Pilmun-daero, Dong-gu, Gwangju 61452, Korea

Tel: +82-62-230-6188

Fax: +82-62-230-6271

E-mail: entvoice@chosun.ac.kr

Received: September 18, 2017

Revised: November 30, 2017

Accepted: December 5, 2017

This study was supported by research fund from Chosun University, 2014

\begin{abstract}
Objectives: The present study investigated the actual conditions of clinical practicums in departments of communication disorders in graduate schools and considers how they can be improved. Methods: A questionnaire composed of 24 questions was sent to 27 graduate schools as an online survey. Results: Of the 25 schools that responded, 21 had clinical practicums in their curriculums. Clinical practicums were usually open to students in their 3rd semester. Most students were trained in practical training centers on campus or speech \& language clinics cooperating with academic institutions. Individuals with developmental language delay and speech sound disorders were the patients who participated in the practicums most frequently. Supervisors were usually professors of the schools and/or speech-language pathologists belonging to an outside institute. They usually supervised 1 to 10 students in a semester and spent 5 or 6 hours on supervisory work in a week. Most of the schools made their students evaluate the degree of satisfaction with the training after the termination of the practicum. Conclusion: Clinical practicums in graduate schools usually involved various patients with different communication disorders and placed students under experienced supervisors. However, there were also some problems, including scheduling for students with jobs and supervisors' heavy workloads. These issues can be addressed through closer cooperation between faculties, students, and supervisors.
\end{abstract}

Keywords: Graduate school, Clinical practicum, Survey
Kim 등(2014)은 언어재활사에 대해 "생애 전반에 걸쳐 나타날 수 있는 말, 언어, 의사소통 문제를 진단평가, 중재, 예방하는 전문 가"로 정의하고 있다. Korea Health Personnel Licensing Examination Institute (2017)는 '언어재활사 직종안내' 중 '개요'에서 “언어 재활사란 생애 발생할 수 있는 의사소통에 어려움이 있는 대상자 들의 중재 및 재활을 담당하는 전문가를 말한다”라고 제시하였으 며 ‘수행직무’에서 “언어재활사는 언어습득 과정이나 언어처리 과 정에 결함을 보임으로써 다른 사람과 원활한 의사소통을 하기 어 려운 사람들에게 전문적인 진단과 훈련을 실시하는 전문가를 말 한다”고 하였다. 여기 언급된 대로 언어재활사가 의사소통에 문제 를 보이는 대상자를 진단하고 중재하는 소임을 충실히 수행하려면 그전에 언어재활사 양성 교육기관에서 양적, 질적으로 적절한 교육 을 받는 것이 필수적이다. 언어재활사 양성 교육기관은 의사소통장
애에 대한 기초적, 전문적 이론지식은 물론 이를 현장에 적용할 수 있는 충분한 실습기회를 제공해야 한다. 우리나라뿐 아니라 대부 분의 국가가 이런 역할을 학부 및 대학원에서 수행하고 있다. 그렇 기 때문에 현재 전국 학부 및 대학원의 언어치료(혹은 병리)학과(이 하, 언어치료학과)는 훌륭한 언어재활사 양성에 막중한 책임을 지 고 있다.

장애인복지법 시행규칙 중 별표6의 2는 언어재활 관련 교과목으 로 모두 이수해야 하는 필수과목 10 개 과목과 9 개 과목 이상 이수 해야 하는 선택과목 23 개 과목을 제시하고 있다. 필수과목은 소위 의사소통장애의 5 대 영역에 해당되는 '신경언어장애, 언어발달장 애, 유창성장애, 음성장애, 조음음운장애'와, 현장실무에 관련된 '의사소통장애 진단평가, 언어재활 현장실무, 언어재활관찰, 언어 진단실습, 언어재활실습이 포함되어 있다(National Law Informa- 
tion, 2017a). 이중 대부분의 학과가 이론과목으로 개설하는 5대영 역 관련 교과목 및 의사소통장애 진단평가는 학교마다 세부적인 내용과 형식은 다르더라도 기본적으로 다루어지는 내용은 크게 다 르지 않다. 그러나 Kim과 Shin (2015)이 실습과목의 경우, 실습과 목의 형식은 대체로 통일된 것처럼 보이나 내용은 대학마다 매우 다 양하다고 언급한 바와 같이, 학교마다 매우 다양한 양상을 보인다.

2011 년 8월 4일 공표된 장애인복지법은 1 급 언어재활사 자격증 취득 자격으로 " 2 급 언어재활사 자격증을 가진 사람으로서 다음 각 목의 어느 하나에 해당하는 사람. 가. 고등교육법」에 따른 대학 원에서 언어재활 분야의 박사학위 또는 석사학위를 취득한 사람으 로서 언어재활기관에 1 년 이상 재직한 사람. 나. 「고등교육법」에 따 른 대학에서 언어재활 관련 학과의 학사학위를 취득한 사람으로서 언어재활기관에 3년 이상 재직한 사람"(National Law Information Center, 2017b)으로 명시하고 있다. 따라서 대학원 진학이 1 급 자격 증 취득의 필수조건이 아닌 지금 대학원에서 이루어지는 언어재활 관찰, 언어진단실습, 언어재활실습의 다양성은 더욱 커졌다. 학부 와 똑같이 자격증 취득 조건을 모두 충족시켜주도록 교과과정을 정하는 학교가 있는가 하면 자격증 취득이 아닌 연구중심의 교과 과정에 중점을 두어 교과과정을 정하는 학교도 있다. 내용은 매우 다양하나 형식은 비슷한 학부와 달리 대학원의 언어진단실습과 언 어재활실습(이하, 임상실습) 과목 운영은 형식조차도 매우 다양하 다. 이런 상황을 보면 대학원의 임상실습운영에 대한 다양한 연구 가 필요하고 이미 선행되었어야 하지만 1992년에 대구대학교 재활 과학대학원에서 처음 언어치료학과 대학원 과정이 개설된 이후 25 년이 지난 역사에 비하면 그 연구는 극히 적다. 각 학과에서 운영되 는 임상실습 프로그램에 대한 기초적인 현황 파악조차 제대로 이 루어지지 않았다.

이에 본 연구는 대학원의 임상실습 교과 연구를 위한 기초연구 로서 언어치료학과 대학원 석사과정에서 운영되는 임상실습 현황 을 파악하고자 하였다. 대학원 언어치료학과의 임상실습 담당교수 를 대상으로 한 설문조사를 통해 대학원에서 임상실습이 어떻게 이루어지는지 파악하고 이를 통해 각 학과가, 언어재활사 공동체가 대학원 임상실습 개선을 위해 어떤 노력을 기울여야 하는지 고찰 해보고자 하였다.

\section{연구방법}

본 연구는 언어치료학과에 대학원 석사과정이 개설된 학과의 임 상실습 담당교수를 대상으로 설문조사를 실시하여 이루어졌다. 이 는 Pyo (2017)에서 시행된 설문조사와 동시에 진행되었기 때문에
설문지 내용구성을 제외한 모든 연구방법은 상기 연구와 동일하 다. 그러므로 여기서 설문지 내용구성을 제외한 다른 연구방법은 중복을 피하기 위해 간략히 소개하도록 할 것이며 설문조사에 응 한 학과의 배경정보 역시 선행연구와 동일하므로 이에 대해서는 연 구대상 부분에서 간략한 소개만 할 것이다.

\section{연구대상}

한국언어청각임상학회, 한국언어치료학회, 한국언어재활사협 회 홈페이지를 참고하여 언어치료학과에 대학원 석사과정이 개설 된 전국 27 개교의 임상실습 담당교수에게 임상실습 현황에 대해 질문하는 설문지를 온라인으로 배포하였다. 모집단의 수가 매우 적 어 설문지의 타당성을 검증해준 교수가 소속된 2 개교도 여기 포함 시켰다. 이중 25 개교에서 응답을 회신하였다.

설문에 응해준 25 개교 중 9 개교는 일반대학원, 15 개교는 특수대 학원에 속해있었다(1개교는 무응답). 계열별로는 자연계열이 10 개 교로 가장 많았고 인문사회계열이 9개교, 기타 계열이 4 개교(보건 계열 2개교, 사범계열 2개교)였다. 학부 전공자가 $50 \%$ 이상인 경우 가 12 개교, 이하인 13 개교로 학부 전공자의 비율은 비슷한 것으로 나타났다.

\section{실험방법}

\section{설문지 작성}

언어치료학과는 물론 현장실습이 이루어지는 다양한 학과(가정 교육학과, 간호학과, 물리치료학과, 보건계열, 식품영양학과, 안경광 학과, 작업치료학과, 치기공학과, 특수교육학과)에서 조사된 실습 현황 연구에 기초하여 설문지를 작성하였다. 이를 통해 1 차적으로 임상실습 관련 설문 문항 25 개가 작성되었다.

이를 대학원이 개설된 언어치료학과 전임교수로서 1 급 언어재활 사 자격증을 소지하고 있으며 현재 임상실습을 담당하고 있고 평 균 12 년 이상 임상 및 임상실습지도의 경력을 가진 2 명의 교수에게 설문지의 타당성을 검토하도록 하였다. 2 명의 검증자가 독립적으로 제시한 수정제안을 바탕으로 1 차 수정본을 작성하였고 이에 대해 각 검증자와 본 연구자가 함께 논의하여 2 차수정과정을 거쳤다. 그 결과 초기 문항에서 임상실습 관련 비용 등 간단히 응답하기 어려 운 2 개 문항을 제외하고 임상실습 시간과 관련된 1 개 문항을 추가 하여 최종 문항 24 개를 확정하였다. 최종 설문지의 내용을 Appen$\operatorname{dix} 1$ 에 제시하였는데 Pyo (2017)와 중복되는 배경정보는 제외하고 임상실습 문항 24 개만 제시하였다. 이 설문지를 네이버 폼 설문조사 양식에 입력하여 온라인을 통한 설문조사가 가능하도록 하였다. 


\section{설문지 배포}

언어치료학과 석사과정이 개설된 학교 27 개교의 임상실습 담당 교수에게 협조를 구하는 메일에 온라인 설문조사의 URL 주소를 링크하여 배포하였다.

\section{분석방법}

회수된 25개교의 응답에 대한 빈도분석을 실시하여 각 문항의 응답 빈도수 및 백분율을 구하였다. 질문에 대한 응답을 보기 중에 서 선택하는 것이 아니고 응답자 스스로가 자유롭게 기록한 경우 비슷한 내용은 하나의 범주에 포함시켜 제시하였다. 그러나 응답자 의 의도와 달리 범주화될 가능성을 배제하기 위해 다르게 해석될 소지가 없다고 판단되는 경우에는 같은 범주에 포함시켰다

\section{연구결과}

\section{언어진단 및 재활실습(임상실습) 교과목 개설 및 운영} 임상실습 시행 여부

전체 25 개교 중 21 개교(84\%)가 임상실습을 시행한다고 응답했 고 4 개교(16\%)가 하지 않는다고 했다. 임상실습을 시행하지 않는 이유에 대해 1 개교는 '모른다'고 답했고, 3 개교는 대학원에 임상실 습 과목을 개설하지 않는 대신 학부과정의 임상실습 과목에서 함 께 실습을 받게 한다고 응답했다. 후자의 경우를 좀 더 자세히 보면 '비전공자의 경우 학부의 임상실습 과목을 수강하게 한다', '자격증 취득을 위한 실습은 학부과정에서 진행하고 소속 랩에서 지도교수 지도 하에 다양한 임상경험을 제공한다', '자격증 취득자가 $90 \%$ 이 상이라 비전공자가 들어올 경우 학부 관찰과 실습을 수강하도록 한다. 대신 임상컨퍼런스를 주내용으로 하는 과목을 개설하여 사 례에 대한 감독을 진행한다'고 했다. 이후의 설문조사 결과는 임상 실습을 시행한다고 한 21 개를 총수로 하여 제시할 것이다.

\section{임상실습 개설 학기}

임상실습 교과목이 제 1 학기에 개설한다고 보고한 경우는 없었 다. 제 2 학기에 개설하는 경우가 3 개교(14\%), 제 3 학기에 개설하는 경우가 12 개(57\%), 제 4 학기 이후에 개설하는 경우가 6 개(29\%)로 제 3 학기에 개설하는 경우가 가장 많았다.

\section{임상실습 교과목 개설 학점 및 시수}

임상실습 교과목 개설 학점에 대한 결과는 Figure 1에 제시하였다.

Figure 1에서 보는 것과 같이 2학점 혹은 3학점으로 개설하는 학 교가 총 13 개교(62\%)로 나타나 절반 이상이 2학점 내지 3학점으로

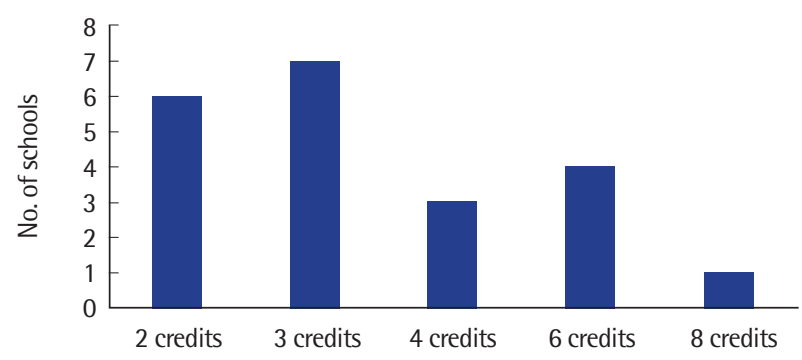

Figure 1. Credits for clinical practicum.

개설하는 것으로 나타났다. 그외 4학점, 6 학점, 8 학점으로 개설되 는 경우가 보고되었는데 이는 임상실습이 2학기 이상 개설될 때 전 체 학점수를 보고한 것으로 파악되었다.

교과목 개설 시수는 2 시수와 3 시수로 보고한 경우가 각각 5 개교 (각 24\%)로 나타났다. 그 외로는 4시수가 2개교(10\%), 6시수가 4개 교(19\%), 8시수가 1개교(5\%)였다. 4개교(19\%)는 시수가 아닌 실습 을 통한 이수시간(90시간)으로 응답했는데 이중 1 개교는 비전공자 는 90 시간, 전공자는 53 시간을 이수하도록 한다고 했다.

\section{임상실습 실습생 선정}

임상실습 교과목 수강생, 즉 실습생을 선정하는 기준에 대해서 는 중복응답이 가능하도록 했으나 중복응답한 학교는 없었다. 전 체 21 개교 중 19 개교(91\%)가 ‘관찰실습 교과목을 이수한 학생'으로 규정하고 있었다. 1 개교(5\%)는 '임상실습능력 검증 시험을 통과한 학생'으로 응답했고 '기타'로 응답한 1 개교(5\%)는 '3학기까지 졸업 에 요구뒤는 전공필수 교과목을 모두 이수한 학생'으로 규정하고 있다고 했다.

\section{임상실습 면제 및 감면 여부}

임상실습을 면제해주는 경우가 있는지에 대한 질문에 '예'라고 응답한 경우는 6 개교(29\%)였고 '아니오'라고 응답한 경우는 15 개 교(71\%)로 나타나 면제해주지 않는 경우가 더 많았다. 면제를 해주 는 것으로 응답한 6개교가 제시한 면제기준은 '학부 전공자'로 응 답한 경우가 3 개교, '학부 전공자로 언어재활사로 근무중인 경우' 가 2 개교, '2급 자격증 소지자 또는 학부에서 임상실습 교과목을 이수한 경우'가 1 개교였다.

장애인복지법 시행규칙 중 별표6의 2에 따르면 "언어진단실습 및 언어재활실습은 총 90시간 이상 이수하여야 한다"고 되어있다 (National Law Information, 2017a). 시행규칙에서 지정한 90시간 에서 일정시간을 감면해주는 경우가 있는지에 대한 질문에 대해 ‘예’로 응답한 경우가 6 개교(29\%), ‘아니오'로 응답한 경우가 15 개교 
(71\%)였다. 감면 기준으로는 '언어재활사 자격증 소지자', ‘학부 전 공자이면서 자격증 소지자'가 각 1 개교였다. '학부 전공자'로 보고 한 경우도 4 개교가 있었는데 이중 2 개교는 '학부 전공자의 경우 $50 \%$ 감면해준다'고 보고하였다.

\section{임상실습 진행 현황}

\section{임상실습 시행장소}

임상실습을 시행하는 장소에 대한 질문에는 중복응답을 허용했 다. 그 결과 가장 많은 곳은 '내부 기관(교내 실습센터)' (20개교, 95\%)이었으며 두 번째로 많은 곳은 ‘학과가 협약한 외부기관' $(12$ 개 교, 57\%)이었다. 그 외 '부속기관(학교 부속의 복지관, 어린이집, 병 원 등)의 언어치료실'이 4 개교(19\%), '학과가 운영하는 외부 치료실' 이 1 개교(5\%)였다. '기타'에 응답한 경우가 2개교였는데 1개교는 추 가기록이 없었고 다른 1 개교는 '자격증 소지자의 경우 본인이 일하 는 치료실'로 기록했다.

\section{임상실습 대상자의 장애영역}

임상실습 대상자의 주된 의사소통장애 영역에 대한 질문에도 중복응답을 허용했다. 그 결과 21 개교 전체(100\%)가 언어발달장애 와 조음음운장애 대상자를 포함한다고 응답했다. 그 다음으로는 유창성장애와 청각장애가 각 15 개교(71\%), 신경언어장애, 마비말 장애, 음성장애가 각 9 개교(43\%), 다문화가정 언어발달지도가 7 개 교(33\%)였다. '기타'는 1개교가 응답했는데 대상자 장애영역을 따 로 기록하지는 않았다.

\section{임상실습을 위한 교내 실습기관(센터) 실습실 수}

임상실습이 외부에서 시행되는 경우에는 실습생을 위해 제공하 는 실습실 수를 정확히 파악하기 어려우므로 이 질문은 교내 실습 기관에 개설된 실습실로 한정하여 응답하도록 하였다. 그 결과를 Table 1에 정리하였다.

위의 표에서 ' 0 '은 교내 실습실이 없다는 의미로 모든 실습이 교 외에서 이루어진다는 의미인데 1 개교가 그러한 응답을 했다. 대체 로 실습실을 1-4개 보유하고 있는 경우가 주류를 이루는 것으로 나 타났다. 10 개를 초과한 실습실 수를 보고한 경우는 1 개교로 14 개 를 보유하고 있다고 했다.

Table 1. Number of practical training rooms (on campus)

\begin{tabular}{lcccccccccccc}
\hline & \multicolumn{1}{c}{ Number of practical training rooms } \\
\cline { 2 - 13 } & 0 & 1 & 2 & 3 & 4 & 5 & 6 & 7 & 8 & 9 & 10 & $>10$ \\
\hline Number of schools & 1 & 3 & 0 & 4 & 3 & 2 & 1 & 0 & 2 & 1 & 3 & 1 \\
\hline
\end{tabular}

대학원 및 학부 임상실습 기관의 중복 여부

전체 21 개교 중 8 개교( $38 \%$ )는 대학원의 임상실습이 학부와 같은 기관(혹은 센터)에서 이루어진다고 보고했다. 그렇지 않다고 한 경 우는 2개교(10\%)였고 나머지 11 개교(52\%)는 학제 내에 학부가 없 어 이에 해당되지 않는다고 보고했다.

학부와 같은 기관에서 임상실습이 이루어진다고 보고한 8개교 모두 학부생과 별도로 대학원생을 위한 실습실이 따로 있다고 보 고했다.

\section{교내 실습기관의 장비 및 지침서 구비 현황}

실습기관에 음성분석기기나 청각검사기기 등의 검사기기(장비), 임상실습 감독 및 실습생을 위한 지침서가 마련되어 있는지 질문하 였다. 이들 질문에 대한 응답은 교내 실습기관으로 한정하였는데 이는 외부 실습기관의 경우 학과가 정확히 현황을 파악하기 어렵기 때문이었다. 전체 21 개교 중 검사기기가 구비되어있다고 응답한 경 우는 15개교(71\%)였고 5개교(24\%)는 구비되어있지 않다고 응답했 다. 나머지 1 개교는 이에 응답하지 않았다.

교내 실습기관에 임상실습 감독을 위한 감독 지침서가 마련되어 있는지에 대한 질문은 15 개교가 마련되어 있다고 응답했고 5 개교 는 그렇지 않다고 응답했다. 1 개교는 모두 외부기관에서 실습을 실 시하기 때문에 이에 해당되지 않는다고 응답했다.

21 개교 중 18 개교(86\%)가 교내 실습기관에 임상실습 실습생을 위한 지침서가 마련되어있다고 보고했다. 3 개교(24\%)는 지침서가 따로 마련되어있지 않다고 했다. 해당사항이 없다고 응답한 경우는 없는 것으로 나타나 모든 실습을 교외에서 진행해도 실습생을 위 한 지침서는 준비되어있는 것으로 파악되었다.

\section{임상실습을 위한 사전교육(오리엔테이션) 실시}

모든 학교가 임상실습을 위한 사전교육을 실시한다고 보고했다. 사전교육을 실시하는 방법으로는 19 개교(91\%)가 강의 형식으로 전달한다고 했고 2개교(10\%)는 '기타'에 응답했다. '기타'에 응답한 학교 중 1 개교는 3 일간의 워크숍(총 15 시간 이상)으로 사전교육을 진행한다고 했고 나머지 응답에서는 별도의 추가기록이 없었다.

\section{임상실습 감독자 현황}

모든 학생의 임상실습 감독을 1 인이 전담해서 하는 경우는 없으 므로 중복응답을 허용했다. 임상실습 감독은 21 개교 전체가 임상 실습 교과목 담당교수가 맡고 있다고 하였는데 이중에는 외부기관 의 언어재활사가 시간강사로서 교과목 담당교수를 겸하고 있는 경 우도 포함되어 있다. 임상실습 교과목 담당교수와 외부기관 소속 언 
어재활사가 함께 감독한다고 보고한 경우가 5개교(24\%)가 있었고 학과의 박사과정 재학생이 함께 하는 경우가 1 개교(5\%)가 있었다. '기타'에 응답한 1 개교(5\%)는 박사학위 소지자인 동시에 1 급 자격 증을 소지한 언어재활사가 함께 임상실습 감독을 진행한다고 했다.

임상실습 감독자의 언어재활사 경력을 Table 2 에 정리하였다. 이 경우에도 다수의 응답이 가능하므로 중복응답을 허용했다.

대학원의 임상실습 감독자는 대부분(90\%) 10 년 이상의 임상경 력을 가진 것으로 보고되었으며 5년 미만의 경력자는 매우 적은 것 (10\%)으로 나타났다.

임상실습 감독자의 1 급 자격증 소지 비율에 대한 응답 결과는 Figure 2와 같다. 그림과 같이 '파악하기 어렵다'로 응답한 2개교 (10\%)를 제외하면 모든 대학원이 1 급 자격증 소지자에 의해 임상실 습이 진행되는 것으로 나타났다.

임상실습 감독자 1 인이 한 학기에 평균적으로 지도하는 실습생 수에 대한 질문의 응답은 매우 다양하게 나타나서 전체 21개교가 제시한 응답이 총 16 가지였다. 이를 좀 더 큰 집단으로 분류하여 7 가지로 정리할 수 있었다. 감독자 1 인당 한 학기 실습생 수가 평균 1-3명이라고 응답한 경우가 5개교(24\%)였고 평균 4-6명, 7-10명으 로 응답한 경우도 각각 5개교(각각 24\%)였다. 평균 3-6명, 5-7명으 로 보고된 경우가 각각 2개교(각각 $10 \%$ )였고, 2-4명, 14 명으로 보고 된 경우가 각각 1 개교(각 $5 \%$ )였다.

Table 2. Practicum supervisors' experience

\begin{tabular}{lc}
\hline Experience (yr) & Number of schools $(\%)$ \\
\hline$<1$ & $0(0)$ \\
$1-5$ & $2(10)$ \\
$5-10$ & $8(38)$ \\
$10-15$ & $12(57)$ \\
$>15$ & $7(33)$ \\
Cannot know & $1(5)$ \\
\hline
\end{tabular}

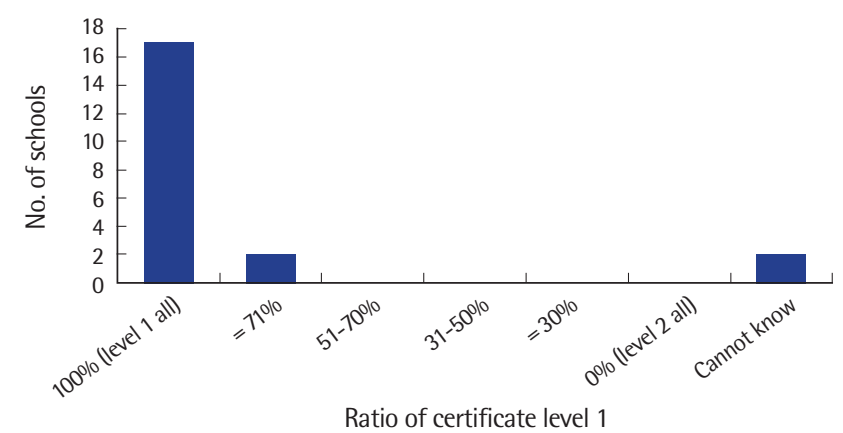

Figure 2. Ratio of supervisors' speech-language pathology certificates (level 1 to level 2).
임상실습 감독자가 1 주일 동안 실습지도를 위해 평균적으로 할 애하는 시간, 즉 직접 및 간접감독, 각종 보고서 피드백, 감독자와 실습생 미팅 등에 할애하는 시간이 어느 정도인지에 대한 질문 또 한 매우 다양한 응답이 제시되었다. 이 응답을 7 가지로 분류해 본 결과 주당 평균 5,6 시간을 할애한다고 한 응답이 가장 많았다(7개 교, 33\%). 다음으로는 주당 3,4 시간을 할애하는 경우가 5 개교(24\%), 10 시간 이상이 4 개교(19\%), 6-8시간이 2개교(10\%)로 나타났다. 그 외 8-10시간, 5-10시간이라고 응답한 경우가 각 1 개교(각 5\%)였고 1 개교는 이 질문에 응답하지 않았다.

임상실습을 직접감독과 간접감독으로 나눌 때 전자는 감독자가 실습생의 실습장면을 실습생과 같은 공간에서 혹은 관찰실에서 실 시간으로 관찰하는 것을 말하고 후자는 실습생의 실습장면을 녹 화한 동영상을 추후에 관찰하는 것을 말한다. 직접감독과 간접감 독의 비율에 대한 응답 결과를 Table 3에 제시하였다.

13 개교 $(62 \%)$ 가 전체 임상실습 감독의 $50 \%$ 이상을 직접감독으로 진행하고 있었고 그중 절반 이상(69\%)이 대부분의 임상감독을 직 접감독으로 하는 것으로 나타났다. 이와 달리 전체 21 개교 중 5 개 교(24\%)는 대부분을 간접감독으로 진행하고 있었고 그중 1 개교는 직접감독 없이 간접감독으로만 임상실습을 진행하고 있는 것으로 나타났다.

\section{임상실습 종료 후 실습사례 발표회}

한 학기의 임상실습이 종료된 후 감독자나 실습생이 개별적으로 실시하는 게 아닌, 학과 차원의 실습사례 발표회를 시행하는지에 대한 질문에 13 개교(62\%)는 '예'로 응답했고 8개교(38\%)는 '아니 오로 응답하였다.

\section{임상실습 평가}

실습생의 임상실습 성적에 대한 평가를 누가 하는지에 대한 질 문에 대해 감독자가 전적으로 평가하는 경우가 1 개교(5\%), 교과목 담당교수가 전적으로 평가하는 경우가 5개교(24\%)였다. 나머지 15 개교(71\%)는 감독자와 담당교수가 둘 다 평가에 참여한다고 보고

Table 3. Ratio of direct supervision to indirect supervision

\begin{tabular}{lc}
\hline & Number of schools (\%) \\
\hline $100 \%$ (all direct supervision) & $2(10)$ \\
$\geq 71 \%$ (much more direct supervision) & $7(33)$ \\
$51 \%-70 \%$ (slightly more direct supervision) & $4(19)$ \\
$31 \%-50 \%$ (slightly less direct supervision) & $3(14)$ \\
$\leq 30 \%$ (much less direct supervision) & $4(19)$ \\
$0 \%$ (indirect supervision all) & $1(5)$ \\
\hline
\end{tabular}


했는데 여기에는 앞서 언급한 것처럼 교과목 담당교수가 임상실습 감독을 겸하고 있어 교과목 담당교수와 임상실습 감독이 동일한 경우도 포함되어 있다.

\section{임상실습 후 실습생 만족도 평가}

임상실습을 종료한 후 실습생들의 만족도를 평가하는지 질문하 였다. 그 결과 13 개교(62\%)가 ‘예'로 응답했고 8개교(38\%)가 ‘아니 오'로 응답했다. 만족도를 평가한다고 응답한 13 개교를 대상으로 중복응답을 허용한 상태에서 평가방법에 대해 질문하였다. 그 결 과 '집담회’를 통해 만족도를 평가하는 경우가 6개교(46\%), ‘체크리 스트 작성'으로 평가하는 경우가 4 개교(31\%), '기타'로 응답한 경우 가 5 개교(39\%)였다. 기타에 포함되어 있는 내용에는 '강의평가로 판단한다(2개교)', '학생들에게 직접 질문해서 구두로 평가한다(1 개교)', '강의평가와 학생들에게 직접 질문한 결과를 참고한다(1개 교)'가 있었고 1 개교는 구체적인 평가방법을 기록하지 않았다.

\section{임상실습 진행 시 애로사항}

임상실습을 진행하는 데 발생하는 애로사항을 특별한 형식 없 이, 가짓수에 상관없이 기록하도록 하였다. 그 결과 '감독에 소요되 는 시간에 비해 학점 및 시수 인정이 제대로 되어 있지 않다(5개교)', '대학원생들의 직장 일정 때문에 실습일정을 잡기가 어렵다(4개 교)', '감독자에게 할애되는 실습생이 너무 많아 꼼꼼한 피드백이 어렵다(2개교), '실습기관 섭외가 어렵다(2개교), '실습대상자가 실 습 도중 그만둘 때 대상자를 재배정하면서 문제가 생긴다(2개교)' 가 2개교 이상이 응답한 내용이었다. 그외 다수가 응답하지는 않았 으나 기록된 애로사항을 나열하면 '실습공간이 부족하다', '임상실 습생의 성실성이 부족하여 문제가 되기도 한다', '좋은 자질을 가진 감독자를 구하기가 어렵다, '비전공자의 경우 학기 중 2 학점만으로 는 국가자격증 시험을 위한 응시조건(임상실습 90 시간 이수)을 채 우기가 어려워 학기중 혹은 방학중 교내 센터에서 실습시간을 채우 고 있다, '국가자격증에 걸맞는 임상실습 감독기준이 제시되어 충 분한 지도가 이루어질 수 있는 정책 전달이 필요하다', '임상실습과 관련된 교재나 진단 및 중재 자료집이 부족하다. 학과가 개별적으 로 만들어 공유하는 것이 아닌, 출판물 형태를 통해 다수가 공유할 수 있는 자료가 필요하다', '학기마다 선발하는 대학원생 수의 변동 이 있는데 학생수가 많을 경우 특히 비전공자가 많을 경우 감독자 의 업무부담이 매우 커진다', '2년동안 관찰실습 및 임상실습을 모 두 마치게 하기가 매우 어렵다' 등이 있었다.

\section{논의 및 결론}

본 연구에서는 언어치료학과에 대학원 석사과정이 개설되어 있 는 학과에서 이루어지는 언어진단 및 재활실습(임상실습) 현황을 파악하고자 해당과정의 임상실습 담당교수를 대상으로 실시하였 다. 그 결과를 간략히 정리하면 아래와같다.

1. 전국에 개설된 언어치료학과 대학원 석사과정 27 개교 중 25 개 교에서 응답을 회신했다. 이중 21 개교(84\%)가 임상실습 과정 을 운영하고 있다고 보고했다.

2. 임상실습 교과목은 제 3 학기에, 한 학기당 2, 3학점과 2, 3 시수 로 개설되는 경우가 많았다. 전체 21 개교 중 19 개교(91\%)가 임 상실습 실습생의 자격조건으로 관찰실습 교과목을 이수한 학 생으로 규정하고 있었다. 대개 임상실습을 면제하거나 감면하 는 규정이 따로 있지 않았으나 일부 학교는 학부 전공자 혹은 자격증 소지자에게 임상실습의 면제 혹은 감면 규정을 적용 하는 것으로 보고되었다.

3. 임상실습은 주로 내부기관(교내 실습센터), 학과와 협약한 외 부 언어치료기관에서 이루어졌다. 임상실습의 실습대상자는 언어발달장애와 조음음운장애(각 21개교 전체), 유창성장애 와 청각장애(각 15 개교)가 주영역을 이루었고 그외 신경언어장 애, 마비말장애, 음성장애, 다문화가정 언어발달지도 대상자가 포함되었다.

4. 임상실습이 이루어지는 교내 실습센터의 실습실 수는 1-4개 인 경우(11개교, $52 \%$ )가 많았다. 교내 실습기관에 검사기기(장 비)가 마련되어 있는 학교는 15 개교(71\%)였다. 교내 실습기관에 임상실습 감독자를 위한 지침서가 있는 학교는 15 개교(71\%)였 고 임상실습 실습생을 위한 지침서가 있는 학교는 18 개교 $(86 \%)$ 였다.

5. 임상실습을 지도하는 임상실습 감독은 외부기관 소속 언어재 활사가 임상실습 교과목 담당교수를 겸하거나 교과목 담당교 수와 외부 언어재활사가 함께 맡는 것으로 나타났다. 대부분 의 임상실습 감독자는 10 년 이상의 임상경력을 갖고 있었으며 (90\%), 1 급 언어재활사 자격증을 소지하고 있었다( $90 \%)$. 감독 자 1 인이 한 학기에 지도하는 평균 실습생 수는 1-10명으로 다 양하게 나타났다. 감독자가 임상실습 감독 업무를 위해 할애 하는 주당 평균시간은 5,6 시간이 가장 많았으나(7개교, $33 \%)$ 이는 학교 및 학과 현황에 따라 매우 다양했다. 임상실습을 직 접감독과 간접감독으로 나눌 때 직접감독이 간접감독보다 더 많이 시행되는 경우(13개교, $62 \%$ )가 그렇지 않은 경우(8개교, $38 \%)$ 보다 더 많았다. 
6. 대부분의 학교가 임상실습 감독자와 임상실습 교과목 담당교 수가 함께 실습생을 평가한다(15개교, 71\%)고 보고했고 임상 실습 후 실습생의 만족도는 13 개교(62\%)가 집담회, 체크리스 트 작성 등, 학생들에게 직접 질문, 강의평가 등을 통하여 평가 하는 것으로 나타났다.

7. 임상실습 진행 시 애로사항으로 '감독자의 양적, 질적 업무 부 담이 크다', '유능한 감독자 및 실습기관의 확보가 어렵다', '직 장과 병행하는 대학원생들의 실습 일정을 잡기가 어렵다'는 등 의 호소가 많았다.

대학원 석사과정에 언어치료학과가 개설되어 있으며 본 설문과 정에 응답한 25 개교 중 4 개교는 임상실습을 시행하지 않는다고 보 고했다. 그 이유에 대해 기록한 3개교는 공통적으로 '임상실습이 필요한 비전공자의 경우 학부에서 실습시간을 이수하도록 한다고 했다. 대학원 석사과정의 언어재활관찰실습(이하, 관찰실습) 운영 에 대해 설문조사를 실시한 Pyo (2017)에서도 언어재활관찰실습 교과목을 개설하지 않는 5 개교 중 3 개교가 학부 과정에서 관찰실 습시간을 이수하도록 한다고 보고했다. 이처럼 학제 안에 학부 과 정을 함께 운영하는 학과의 경우 대학원 실습을 보다 더 융통성 있 게 활용할 수 있다. 학부 과정에서 관찰 및 임상실습이 진행될 경우 대학원 과정은 실습 교과목 개설 및 운영을 위한 시간 및 경비에서 자유로울 수 있으므로 대학원 과정 본연의 목적인 연구에 더 충실 한 교과과정을 진행할 수 있다.

그러나 본 설문에서 임상실습을 시행한다고 보고한 21 개교 중 11 개교가 학제 내 학부과정이 없다고 응답하여 10 개교는 관찰실습 및 임상실습을 모두 대학원 과정 중에 진행해야 하는 것으로 나타 났다. 임상실습을 시행하는 목적이 자격증 취득인 경우 대학원 2년 과정 동안 필요한 실습시간 90 시간을 모두 이수하는 것은 매우 어 렵다. 현장근무와 대학원 수학을 병행하는 학생이 많은 특수대학 원의 경우 그 어려움은 배가 된다. 이는 애로사항 중 '대학원생들의 직장 일정 때문에 실습 일정을 잡기가 어렵다'는 호소가 다수 나타 난 것만으로도 충분히 짐작할 수 있다. 이러한 경우가 실습대상자 가 사정에 따라 갑자기 치료 일정을 바꾸거나 갑자기 치료를 중단 하는 등 예상하지 못한 일과 겹쳐 나타나면 그 고충은 더욱 커진다. 이를 위해서는 실습생을 위한 임상실습 지침서에 이와 같은 경우 의 내규를 포함시켜 숙지 및 준수하도록 해야 한다. 또한 실습대상 자를 위한 지침서 혹은 협조문을 함께 제작, 배포하여 실습대상자 및 보호자의 협조도 최대한 구해야한다.

임상실습을 개설하는 학기는 제 2 학기에서 제 4 학기 이상까지 다 양하게 나타났으나 가장 높은 빈도를 보인 경우는 제 3 학기였다. 이 는 Pyo (2017)의 연구에서 관찰실습을 제 2 학기에 개설한다고 보고
한 경우가 전체 20 개교 중 11 개교로 나타난 것과 연관성이 깊다. 본 설문조사에서 임상실습생을 선정하는 기준으로 전체 중 19 개교 (91\%)가 '관찰실습 교과목을 이수한 학생'으로 하고 있었으므로 대 부분의 대학원 과정이 제 2 학기에 관찰실습, 제 3 학기에 임상실습 교 과목을 개설하는 것으로 보여진다.

임상실습은 주로 교내 실습센터나 학과 협약기관(대개 사설 언 어치료실)에서 이루어지는 것으로 보고되었다. 임상실습 대상자 중 대다수가 언어발달장애, 조음음운장애, 유창성장애, 청각장애 를 동반하는 것으로 보고되었으며 신경언어장애나 음성장애를 동 반한 대상자는 상대적으로 적었다. 실습 대상자의 이러한 추세는 실습장소와 연관성이 깊다. 정기적인 병원 진료나 추후관찰이 필요 한 신경언어장애나 음성장애, 구개열 동반 대상자는 대개 병원 소 속의 언어치료실을 선호하므로 학교 안에 있는 실습센터나 사설 언 어치료실에 내원하는 경우는 흔치 않다. 기관 자체에 내원하는 대 상자 수가 적으므로 소수의 실습생만이 이런 대상자의 실습기회를 경험하게 된다. 따라서 대부분의 실습생은 신경언어장애나 음성장 애를 동반한 대상자의 임상실습 기회가 거의 없이는 추후 의사소 통장애의 세부전공 선정, 혹은 졸업 후 취업하고자 하는 세팅 선정 에도 영향을 미친다.

Lee 등(2004)은 작업치료학과의 임상실습 교육 현황을 파악하 는 연구에서 임상실습 교육이 졸업 후 진로를 선택하는 데 중요한 역할을 하며 작업치료에 대한 종합적 안목을 키울 수 있다고 했다. Lee와 Kim (2008)은 임상실습 후 실습생의 경험 습득 정도가 학생 들의 수행 자신감에 영향을 미친다고 했다(as cited in Lee, Shin, \& Jung, 2010). Kim과 Lee (2009)는 언어치료 임상실습교육 모형 개발 연구에서 임상실습 및 심화 임상실습 교육이 자신의 취업 및 업무 에 도움이 된다고 한 임상실습생의 보고를 언급했다. 이렇듯 어떤 의사소통장애 대상자를 대상으로 임상실습을 했는가는 대학원생 의 경우 졸업 후 취업은 물론 학위논문 주제를 선정할 때도 중요한 역할을 한다. 대부분의 학생은 자신이 임상실습에서 접한 장애군 을 더 친숙하게 생각하므로 그러한 장애군을 대상으로 한 연구주 제를 선정하는 경우가 빈번하다. 이러한 경향이 심화되면 임상실습 에서 자주 접하기 어려운 장애군은 미래의 유능한 연구인력을 확 보하는 데에도 어려움이 생길 수 있으므로 적극적인 대책이 필요하 다. 예를 들어 그런 장애군에 대한 연구를 희망하는 학생의 경우 해 당 대상자군을 주로 치료하는 기관과의 협약을 통해 임상실습 기 회를 제공하는 방법도 있다. 대부분의 학생은 자신이 연구하고자 하는 장애군을 전공한 교수가 전임으로 있는 학교를 선택하지만 일부는 여건상 그러지 못하는 경우도 있다. 그런 경우 얼마 안되는 소수의 학생을 위해 기관 협약을 하기는 어려우므로 해당 전임교수 
가 있는 학교와 연계를 통해 상호협력하는 체계를 구축하는 것도 고려해볼수 있다.

임상실습생의 실습지도를 맡는 감독자의 역할은 매우 크다. Kim 과 Shin (2015)은 임상실습에서 실습지도자의 역할이 매우 중요하 며 교수변인이 학습자의 학습성과에 지대한 영향을 미친다고 했다. 작업치료학과의 임상실습 현황을 파악한 Kim과 Kang (2004)은 실습지도자가 갖추어야 할 최소기준으로 작업치료학과 전임강사 이상의 응답자 중 $50 \%$ 가 임상경험, $36 \%$ 가 인성이라고 지적했다. 이 렇듯 학교 기관에서는 다양한 경험을 통해 얻은 지식으로 실습생 들이 직면하게 되는 문제 해결을 돕고 실습생에게 세심한 피드백을 제공해줄수 있는 감독자가 임상실습 지도를 맡아주기 바란다.

언어치료학과 학과인증제를 위해 기초연구를 실시한 Kwon 등 (2010)의 연구에서 전문대, 학부, 대학원을 대상으로 임상실습 현 황을 분석한 결과 감독자가 소지한 자격증을 1 급으로 제한하고 있 었고 전체 38 개교 중 29 개교가 3 년 이상의 임상경력을 갖고 있는 경 우로 제한한다고 보고했다. 2011년 언어재활사 자격증이 국가자격 증이 되고 언어재활사 자격증 전반에 대한 시행이 장애인복지법의 적용을 받는 2017년 현재 1 급 자격증과 2 급 자격증의 업무가 명확 히 구분되어 있지 않다. 본 연구결과 대부분의 학교(17개교)가 모든 감독자가 1 급 자격증 소지자라고 보고했으나 적은 수이긴 하나 2 개 교는 2 급 자격증 소지자가 포함되어있다고 했다. 이는 적합한 임상 실습 감독자를 확보하기가 어려운 현실을 반영한다고 볼 수 있는데 또 다른 2 개교가 감독자가 소지한 자격증의 급수를 파악하지 못하 고 있다고 보고한 것도 같은 맥락이다. Lee 등(2004)은 작업치료 실 습기관 확보가 어렵다 보니 임상실습교육의 질에 대한 관리가 소홀 함을 지적했는데 이와 비슷한 지적이 언어치료에도 적용된다. 즉 적합한 실습감독자를 확보하기 어려우니 비록 초기에는 높은 수준 의 감독자 선정 기준을 정했다고 해도 현실에 맞추어 점차 그 기준 을 완화시킬 수밖에 없는 것이다. Koo와 $\operatorname{Im}$ (2013)이 간호대학생의 임상실습 만족도를 연구한 논문에서도 실습기관 선정과 실습지도 자 확보가 어려움을 언급하였다. 이를 보면 이는 언어치료학과, 작 업치료학과뿐 아니라 그보다 인력 풀(pool)이 훨씬 더 큰 간호학과 에서도 적합한 임상실습 감독자 선정이 쉬운 일이 아님을 짐작할 수 있다.

임상실습의 애로사항 중 감독에 할애하는 시간과 노력에 비해 합당한 대우를 해줄 수 없음을 지적한 내용이 많았는데 이것이 감 독자 확보를 어렵게 하는 요인이 될 수도 있다. 우리나라 언어치료 학과의 임상실습 감독자 중 오직 임상실습 감독만을 하는 경우는 극히 드물다. 한 학교의 전임교수이거나 언어치료기관의 책임자 혹 은 운영자인 경우가 대부분이다. 이들에게 임상실습 감독자의 역할
은 이들이 해야 하는 일의 일부이며 이들은 이외에 해야 할 더 많은 일들이 있다. 이러한 감독자들이 1주 동안 평균적으로 임상실습 감 독을 위해 할애하는 시간은 5,6 시간이 가장 많았고 감독자 1 인이 평균적으로 감독하는 실습생 수는 적게는 1 명에서 많게는 14 명으 로 보고되었다. 그리고 대부분의 감독자가 간접감독보다 직접감독 을 더 많이 시행하는 것으로 나타났다. 이는 일반적인 경향에 대한 보고이고 실습생 수는 학기마다 달라질 수 있으며 실습생 중 학부 비전공자가 포함될 경우 할애하는 시간과 노력은 훨씬 더 증가한 다. 이에 비해 임상실습 교과목의 학점 및 시수는 학기당 2,3 학점과 2,3 시수가 대부분인데 이는 감독자가 감독하는 실습생 수에 따라 시수가 달라진다든가 하지는 않는다. 더구나 정해진 시간에 감독하 는 것과 별도로 실습생이 조언을 구하기 위해 수시로 보내는 이메 일이나 문자 등에 답변하는 것도 부담이 큰 업무이다. 이러한 문제 의 해결을 위해서는 학과가 임상실습 감독자의 애로사항을 잘 파 악하고 학교 및 학과의 상황에 맞게 적절한 해결책을 함께 모색하 는 것이 가장 현실적인 방법이다. Kim과 Shin (2015)이 학부를 대상 으로 한 연구에서 언어치료실습 감독자 중 전임교수의 비율이 $65.9 \%$ 라고 보고한 것처럼 대부분의 감독자가 학과 소속 교수인 경우가 많아 관찰실습에 비하면 임상실습은 학과와 감독자 간의 협조가 비교적 잘 이루어지는 것으로 보인다. 학과는 학과 차원에서 할 수 있는 최대한의 지원을 임상감독자에게 제공할 수 있도록 노력하고 필요한 경우 학교의 지원을 적극적으로 요청해야 한다. 또한 임상 실습 감독자는 실습지도의 애로사항을 적극적으로 학과에 전달하 여 적극적, 능동적으로 문제점을 해결하도록 노력해야 한다.

임상실습 평가는 임상실습 감독자와 교과목 담당교수가 함께 실 시하는데 대개 이 둘의 역할을 학과 전임교수가 병행하는 경우가 많았다. Lee 등(2004)은 임상실습 평가는 감독자 주관에 따라 이루 어지기 때문에 감독자간 공정성, 형평성에 문제가 있을 수 있다고 했다. 한 학과에서 시행하는 임상실습 감독자 중에는 학과의 전임 교원로서 이미 실습생에 대해 잘 아는 감독자도 있고 외부기관 소 속의 언어재활사로서 실습생을 처음 보는 감독자도 있다. 이런 경 우 두 종류의 감독자가 서로 같은 기준으로 실습생을 평가하기는 어려울수 있다.

Kim, Park, Lee와 Yoo (2007)는 예비 특수교사의 교육실습 운영 에 대한 실태 분석 연구에서 교육실습을 통해 실습생들은 자신의 교육자적 능력과 교직에 대한 적성 여부를 최종 점검해볼 수 있다 고 했다. 이는 예비 언어재활사의 경우도 마찬가지다. 임상실습 평가 결과 낮은 점수를 받은 실습생은 상대적으로 언어치료에 대한 자신 의 능력 및 적성을 의심해볼 수 있다. Lee, Park과 Park (2015)은 언 어재활과 학생들의 실습불안에 대한 연구 결과, 대상자 상호작용과 
실습 평가 영역에서 불안을 보인다고 했다. 이를 위해서는 임상실습 교과목 개설 시 제시하는 종합적 평가기준 외에 감독자마다의 평가 기준에 대해 사전에 제시해주는 것이 필요하다. Lee, Kim과 Kim (2004)도 간호학생의 임상실습 만족도에 대한 연구에서 평가에 대 한 만족도를 높이려면 평가방법 혹은 평가기준을 미리 알려주는 것 이 효과적이라고 했다. 임상실습 감독자는 적절하고 공정한 평가 기 준을 사전에 제시하고 실습생은 이를 실습 초기부터 숙지하여 효과 적인 임상실습 및 감독이 이루어지도록 노력해야한다.

임상실습 후 실습생의 만족도 조사는 중요하다. Jun (1984)은 일 부 학생의 경우 임상실습 후 자신이 선택한 학문의 만족도 정도가 낮아지기도 한다고 했다(as cited in Lee et al., 2010). Kim과 Lee (2009)는 경험 중심의 실습교육 과정은 교수자와 학생이 교육과정 에 대해 지속적으로 평가와 피드백을 제공하는 것이 필수적이라고 했다. 본 연구 결과 전체 21 개교 중 만족도를 평가하는 학교가 더 많 았지만(13개교) 그렇지 않은 학교도 8개교(38\%)에 달하였다. 한 학 기의 실습과정을 마치고 이에 대해 학과의 자체평가는 물론 실습생 의 만족도 조사를 통해 유지해야 할 점과 개선해야 할 점을 파악하 고 이 결과를 다음 학기 실습 계획에 적극 반영하는 것이 필요하다.

본 연구는 설문조사를 통해 대학원 언어치료학과 석사과정에서 이루어지는 임상실습 현황을 파악하고자 하였다. 우리나라 언어치 료학과 학부생의 임상실습 현황은 다양한 측면에서 다양한 연구가 이루어졌으나 대학원에서 이루어지는 임상실습 현황 연구는 매우 드물다. 대학원 임상실습의 발전을 위해서는 기본적인 임상실습의 현황 파악이 먼저 이루어져야 하고 그 후에 양적 및 질적으로 더 심 도 깊은 추후연구가 이루어져야 한다. 이러한 측면에서 볼 때 본 연 구는 대학원 임상실습의 기초 현황을 파악, 정리하여 제시했다는 데 연구의 의의가 있다.

그러나 본 연구는 대학원 임상실습에 대한 기초연구로서 현황 파악에 목적을 두고 있다 보니 현황에 대한 양적 대한 보고가 주류 를 이루고 있다. 이제 이를 바탕으로 하여 더 많은 추후연구가 필요 하다. 본 연구에서 제시된 기초 현황 외에 보다 더 세밀한 현황 조사 가 필요하다. 임상실습 기관의 검사도구, 치료도구 및 검사장비 구 비 현황, 실습대상자의 확보 방법, 임상실습 평가 기준 등에 대한 연 구가 필요하다. 민감한 사안이어서 쉽게 접근하기 어려우나 필요한 연구 중의 하나는 실습경비에 대한 건이다. 실습경비를 어떻게 확보 하고 어떻게 지출하는지, 실습생 지원은 어떻게 하는지 등에 대한 연구가 필요하다는 것도 조심스럽게 제안한다.

연구대상을 임상실습 감독자에서 임상실습 수혜자인 대학원생 으로 전환시킬 필요도 있다. 임상실습에 대해 대학원생들이 어느 정도 만족하고 있고 어떤 견해를 갖고 있는지에 대한 심도 깊은 연
구가 이어져야 한다. 또한 연구방법을 달리 하여 오랜 기간 동안 임 상실습 진행을 맡아온 전문가들을 대상으로 한 질적 연구도 진행 해볼 수 있다. 이를 통하여 대학원에서 이루어지는 임상실습에 대 한 보다 더 정확한 파악을 통해 임상실습 감독자와 수혜자 모두에 게 더 나은 임상실습이 진행될 수 있도록 해야 할 것이다.

\section{REFERENCES}

Kim, H. Y., Park, K. O., Lee, T. S., \& Yoo, J. Y. (2007). A survey on practicum for pre-service special education teachers. Journal of Special Education: Theory and Practice, 8, 419-443.

Kim, J. K., \& Kang, D. H. (2004). The survey on the perception of occupational therapy faculty on the clinical fieldwork. Journal of Korean Society of Occupational Therapy, 12, 91-103.

Kim, S. J., \& Lee, S. H. (2009). The development and evaluation of a clinical skill-based curriculum model for speech therapy. Korean Journal of Communication \& Disorders, 14, 413-428.

Kim, S. Y., \& Shin, M. S. (2015). A study of the satisfaction and teaching efficiency of clinical practice of students majoring in speech-language pathology. Journal of Speech-Language \& Hearing Disorders, 14, 17-31.

Kim, Y. T., Kim, J. O., Jeon, H. S., Choi, H. J., Kim, M. J., Kim, T. W., \& Kang, M. K. (2014). Job analysis of Korean speech-language pathologists using Delphi study. Journal Speech-Language, \& Hearing Disorders, 23, 147-161.

Koo, H. Y., \& Im, H. S. (2013). Comparison of factors influencing satisfaction of clinical practice between associate and bachelor nursing students. Journal of the Korea Contents Association, 13, 311-321.

Korea Health Personnel Licensing Examination Institute. (2017). Job description for speech-language pathologists. http://www.kuksiwon.or.kr/ Examination/OccuLicense.aspx?PageName=LicensInfo\&JobCode=37\&Si teGnb $=8 \&$ SiteLnb $=1$

Kwon, S. B., Kim, S. J., Pae, S. Y., Yoon, H. R., Hwang, M. A., \& Shin, M. S. (2010). A basic study for department of speech pathology certification with a focus on the educational environment. Journal of Speech-Language \& Hearing Disorders, 19, 1-23.

Lee, M. J., Kim, K. M., Lee, J. S., Lee, T. Y., Kang, D. H., Lee, K. S., \& Yoo, E. Y. (2004). The current fieldwork affiliation status of the occupational therapy education programs in Korea. Journal of Korean Society of Occupational Therapy, 12, 105-117.

Lee, M. S., Park, H., \& Park, C. H. (2015). A study of correlation between self-efficacy and practice-related anxiety of students majoring in speech 
rehabilitation. Journal of Speech-Language \& Hearing Disorders, 24, 147158.

Lee, O. J., Shin, J. A., \& Jung, S. H. (2010). A study on the clinical practice in ophthalmic optics. Journal of Korean Ophthalmic Optics Society, 15, 319328.

Lee, S. H., Kim, S. Y., \& Kim, J. A. (2004). Nursing students' image of nurse and satisfaction with clinical practice. Journal of Korean Academy of Nursing Administration, 10, 219-231.

National Law Information Center. (2017a). Enforcement of the Act on welfare of persons with disabilities. http://www.law.go.kr/lsSc.do?menuId=0\& $\mathrm{p} 1=\&$ subMenu $=1 \& \mathrm{nw} \mathrm{Yn}=1$ \&section $=\&$ tabNo $=\&$ query $=\% \mathrm{EC} \% 9 \mathrm{E} \% \mathrm{~A} 5$ \%EC\%95\%A0\%EC\%9D\%B8\%EB\%B3\%B5\%EC\%A7\%80\%ЕB\%B2\%95\# undefined

National Law Information Center. (2017b). Act on welfare of persons with disabilities. http://www.law.go.kr/lsSc.do?menuId=0\&p1=\&subMenu=1\& $\mathrm{nwYn}=1 \&$ section $=\& \operatorname{tabNo}=\&$ query $=\% \mathrm{EC} \% 9 \mathrm{E} \% \mathrm{~A} 5 \% \mathrm{EC} \% 95 \% \mathrm{~A} 0 \% \mathrm{EC} \%$ 9D\%B8\%EB\%B3\%B5\%EC\%A7\%80\%EB\%B2\%95\#undefined

Pyo, H. Y. (2017). A survey on clinical observation in graduate schools. Communication Sciences \& Disorders, 22, 421-433. 
Appendix 1. 대학원 석사과정 임상실습 설문지

안녕하십니까? 조선대학교 언어치료학과 표화영입니다.

바쁘신 와중에 설문에 응해주셔서 대단히 감사합니다.

본 설문지는 대학원 석사과정에서 시행되는 관찰실습(언어재활관찰)과 임상실습(언어진단실습 및 언어재활실습)이 학과마다 매우 다양하게 이루어지고 있는 현 시 점에서 그 현황을 파악하고자 제작되었습니다.

설문에 대해 사실 그대로의 답변을 빠짐없이 기록해 주시기 부탁드립니다.

응답해 주신 내용은 분석을 위해서만 사용되며 학교 및 학과정보의 외부 노출은 절대로 없을 것입니다.

다시 한 번 협조에 감사드리며 문의사항이 있으시면 언제든 아래 연락처로 연락 주시기 바랍니다.

조선대학교 언어치료학과 표화영

\section{I. 언어진단실습 및 언어재활실습}

1. 귀 학과는 석사과정 학생에게 언어진단 및 언어재활실습(이하, 임상실습)을 시행합니까?

1) 예 - 2번으로 가십시오

2) 아니오-1-1번으로 가십시오

1-1. 임상실습을 시행하지 않는 이유를 간략히 쓰신 후 '제출하기’를 눌러주십시오.

2. 임상실습을 시작하는 학기는 언제입니까?
1) 제 1 학기
2) 제2학기
3) 제 3 학기
4) 제4학기 이후

3. 임상실습 교과목의 학점 및 시수는 어떻게 됩니까?

4. 임상실습의 실습생은 어떻게 선정하십니까?

해당사항에 모두 체크해주십시오.(기타일 경우 간략히 써주십시오)

1) 관찰실습 교과목을 이수한 학생

2) 임상실습 능력 검증 시험을 통과한 학생

3) 기타:

5. 임상실습을 면제해주는 경우도 있습니까?
1) 예 - 5-1번으로 가십시오
2) 아니오 - 6번으로 가십시오

5-1. 임상실습 면제의 기준은 무엇입니까? 간략히 써주십시오.

6. 임상실습 이수시간을 줄여주는(감면해주는) 경우가 있습니까?
1) 예 - 6-1번으로 가십시오.
2) 아니오 - 7번으로 가십시오

6-1. 임상실습 감면의 기준은 무엇입니까? 간략히 써주십시오. 
7. 임상실습은 어디에서 시행하십니까? 해당사항에 모두 체크해주십시오.(기타일 경우 간략히 써주십시오)

1) 내부 기관(교내 실습센터)

2) 부속기관(학교 부속 복지관, 어린이집, 병원 등)의 언어치료실

3) 학과가 운영하는 외부 치료실

4) 학과 협약기관의 치료실

5) 기타:

8. 임상실습 대상자의 장애 영역은 무엇입니까? 해당사항에 모두 체크해주십시오. (기타일 경우 해당영역을 써주십시오)
1) 언어발달장애
2) 조음음운장애
3) 신경언어장애
4) 마비말장애
5) 유창성장애
6) 음성장애
7) 청각장애
8) 다문화 가정 언어발달지도

9) 기타:

9. 임상실습을 위한 교내 실습센터 내에 실습실은 몇 개입니까? 교내에 임상실습실이 없으면 (모두 외부기관에서 실시하면) 0으로 해주십시오.

10. 학부생과 같은 공간에서 임상실습이 진행됩니까?
1) 예 - 10-1번으로 가십시오
2) 아니오 - 11번으로 가십시오
3) 해당사항 없음(학제 내 학부가 없다)

10-1. 대학원생을 위한 실습실이 따로 있습니까?
1) 예
2) 아니오

11. 교내 실습기관(실습실 혹은 센터)에 음성분석기기나 청각검사기기 등의 검사기기가 마련되어 있습니까? (외부 기관은 학과가 파악하기 어려우니 교내로 한정합니다)
1) 예
2) 아니오

12. 교내 실습기관에 임상실습을 위한 감독 지침서가 마련되어 있습니까? (외부 기관은 학과가 파악하기 어려우니 교내로 한정합니다)
1) 예
2) 아니오
3) 해당사항 없음(모두 외부기관에서 실시)

13. 교내 실습기관에 임상실습 실습생을 위한 지침서가 마련되어 있습니까? (외부 기관은 학과가 파악하기 어려우니 교내로 한정합니다)
1) 예
2) 아니오
3) 해당사항 없음(모두 외부기관에서 실시)

14. 임상실습을 위한 사전교육(오리엔테이션)을 실시하십니까?
1) 예 - 14-1번으로 가십시오
2) 아니오 - 15번으로 가십시오

14-1. 사전교육은 어떻게 실시하십니까?(기타일 경우 간략히 써주십시오)

1) 강의식으로 교육 2) 이메일 등으로 유인물 전달

3) 기타

15. 임상실습 감독은 주로 누가 시행합니까?

해당사항에 모두 체크해주십시오. (기타일 경우 누가 시행하는지 기록해주십시오)
1) 임상실습 교과목 담당교수
2) 외부기관 소속 언어재활사
3) 박사과정 재학상
4) 기타: 
16. 임상실습 감독자의 언어재활사 경력은 대략 어느 정도 됩니까? 해당사항에 모두 체크해주십시오.
1) 1 년 미만
2) 1 년 이상-5년 미만
3) 5 년 이상-10년 미만
4) 10년 이상-15년 미만
5) 15 년 이상
6) 파악하기 어렵다

17. 임상실습 감독자의 1 급 자격증 소지자 비율은 대략 어느 정도 됩니까?

1) 감독자 전원 (1급 소지자 $100 \%)$

2) 전체 중 1급 자격증 소지자가 $71 \%$ 이상 (모두는 아니나 2급 소지자보다 훨씬 많은 편이다)

3) 전체 중 1급 자격증 소지자가 $51-70 \%$ (2급 소지자에 비해 절반 조금 넘는다)

4) 전체 중 1급 자격증 소지자가 $31-50 \%$ (2급 소지자에 비해 절반 조금 안 된다)

5) 전체 중 1급 자격증 소지자가 $30 \%$ 이하 (전혀 없는 것은 아니나 2급 소지자보다 훨씬 적은 편이다)

6) 파악하기 어렵다.

18. 임상실습 감독자 1 인이 한 학기에 감독하는 실습생 수는 대략 평균 몇 명입니까?

19. 임상실습 감독자는 감독을 위해 주당 평균 몇 시간을 할애하십니까(직접 및 간접감독, 보고서 피드백, 감독자 미팅 모두 포함)?

20. 직접감독(감독자가 실습장면을 직접 관찰)과 간접감독(녹화된 동영상 추후 시청)의 비율은 대략 어느 정도입니까?

1) 전체를 직접감독으로 함 (직접감독 100\%)

2) 전체 중 직접감독이 $71 \%$ 이상 (모두는 아니나 간접감독보다 횔씬 많은 편이다)

3) 전체 중 직접감독이 $51-70 \%$ (간접감독에 비해 절반 조금 넘는다)

4) 전체 중 직접감독이 31-50\% (간접감독에 비해 절반 조금 안 된다)

5) 전체 중 직접감독이 $30 \%$ 이하 (전혀 없는 것은 아니나 간접감독보다 훨씬 적은 편이다)

6) 전체를 간접감독으로 함 (간접감독 $100 \%$ )

21. 한 학기 실습종료 후 학과 차원의(감독자가 개별적으로 실시하는 것이 아닌) 사례발표회를 실시하십니까?
1) 예 2) 아니오

22. 임상실습 평가는 누가 실시하십니까?(기타일 경우 간략히 써주십시오)
1) 감독자
2) 교과목 담당교수
3) 감독자 및 교과목 담당교수 둘 다
4) 기타:

(1)

23. 임상실습 후 학생들의 만족도 평가를 실시하십니까?
1) 예 - 23-1번으로 가십시오
2) 아니오 - 24번으로 가십시오

23-1. 만족도를 평가하는 방법은 무엇입니까? 해당사항에 모두 체크하십시오.(기타일 경우 간략히 써주십시오)
1) 집담회
2) 체크리스트 작성
3) 기타:

24. 임상실습을 진행하는 데 애로사항이 있으시면 써주십시오.

* 설문을 도와주셔서 대단히 감사합니다. 


\section{국문초록}

\section{언어치료학과 대학원 석사과정의 언어진단 및 언어재활실습 현황 연구 표화영}

조선대학교 언어치료학과

배경 및 목적: 본 연구는 설문조사를 통하여 대학원 언어치료학과 석사과정에서 시행되는 언어진단 및 재활실습(이하, 임상실습) 현황 에 대해 파악하고 이를 통해 대학원 임상실습이 앞으로 나아갈 점을 숙고해보고자 하였다. 방법: 대학원에 언어치료 석사과정이 개설 된 전국 27 개교의 임상실습 담당교수에게 24 개 문항의 온라인 설문지를 링크시킨 이메일을 통해 설문에 참여하도록 하였다. 결과: 27 개교 중 25 개교에서 회신을 보냈고 이중 21 개교에서 임상실습을 시행한다고 하였다. 임상실습 과목은 대개 관찰실습을 이수한 학생을 대상으로 제 3 학기에 시작하였다. 임상실습은 주로 교내 실습센터나 학과 협약 언어치료기관에서 이루어졌다. 임상실습의 대상자군은 언어발달장애군과 조음음운장애군이 가장 많았다. 임상실습은 주로 교과목 담당교수와 외부 언어재활사가 감독하는 것으로 나타났 다. 이들은 학기당 평균 1-10명의 실습생을 감독하며 주당 5,6 시간을 감독관련 업무에 할애하는 것으로 나타났다. 대다수 학교가 실습 종료 후 다양한 방법을 통해 실습생의 만족도를 조사하고 있었다. 논의 및 결론: 대학원 임상실습은 대체로 경험 많은 언어재활사의 감 독 하에 다양한 의사소통장애군을 대상으로 시행되는 것으로 나타났다. 그러나 취업 중인 실습생의 실습 일정, 감독자의 과중한 업무 부담 등의 어려움도 겪고 있는 것으로 나타났다. 이를 해결하기 위해 학과와 실습생, 감독자 간의 긴밀한 협조가 필요하다.

핵심어: 대학원, 언어진단실습, 언어재활실습, 임상실습, 설문조사

본 연구는 2014년도 조선대학교 학술연구비의 지원을 받아 연구되었음.

\section{참고문헌}

구현영, 임형석(2013). 학제별 간호대학생의 임상실습 만족도에 미치는 영향 비교. 한국콘텐츠학회논문지, 13,311-321.

국가법령정보센터(2017a). 장애인복지법 시행규칙. http://www.law.go.kr/lsSc.do?menuId = 0\&p1 = \&subMenu = $1 \& n w Y n=1 \& s e c t i o n=\& \operatorname{tabNo}=$ \&query $=\% \mathrm{EC} \% 9 \mathrm{E} \% \mathrm{~A} 5 \% \mathrm{EC} \% 95 \% \mathrm{A0} \% \mathrm{EC} \% 9 \mathrm{D} \% \mathrm{~B} 8 \% \mathrm{~EB} \% \mathrm{~B} 3 \% \mathrm{~B} 5 \% \mathrm{EC} \% \mathrm{~A} 7 \% 80 \% \mathrm{~EB} \% \mathrm{~B} 2 \% 95 \#$ undefined

국가법령정보센터(2017b). 장애인복지법. http://www.law.go.kr/lsSc.do?menuId = 0\&pl = \&subMenu=1\&nwYn = $1 \&$ section $=\&$ tabNo $=\& q u e r y=$

\%ЕC\%9E\%A5\%ЕC\%95\%A0\%EC\%9D\%B8\%EB\%B3\%B5\%EC\%A7\%80\%EB\%B2\%95\#undefined 권순복, 김수진, 배소영, 윤혜련, 황민아, 신명선(2007). 언어치료학과 학과인증제를 위한 기초 연구: 교육환경 중심으로. 언어치료연구, 19, 1-23. 김수진, 이수향(2009). 언어치료 임상실습 교육모형 개발 및 적용. 언어청각장애연구, 14, 413-428. 김시영, 신명선(2015). 언어치료 전공학생의 임상실습 만족도 및 교수효율성 연구. 언어치료연구, 24, 17-31. 김영태, 김재옥, 전희숙, 최현주, 김민정, 김태우, 강민경(2014). 델파이 조사를 통한 언어재활사 직무분석 연구. 언어치료연구, 23, 147-161. 김진경, 강대혁(2004). 작업치료(학)과 교수를 대상으로 한 임상실습에 관한 연구. 대한작업치료학회지, 12, 91-103. 김호연, 박경옥, 이태수, 유재연(2007). 예비특수교사의 교육실습 운영 실태 분석 및 인식 조사. 특수교육저널: 이론과 실천, 8, 419-443. 이명순, 박현, 박찬희(2015). 언어재활과 학생들의 자기효능감과 실습불안에 대한 상관관계 연구. 언어치료연구, 24, 147-158. 이미자, 김경미, 이재신, 이택영, 강대혁, 이경식, 유은영(2004). 작업치료 교육에 있어서 임상실습 교육 현황 분석. 대한작업치료학회지, 12, 105-117. 이순희, 김숙영, 김정아(2004). 간호학생의 간호이미지와 실습만족도. 간호행정학회지, 10, 219-231. 이옥진, 신진아, 정세훈(2010). 안경광학과 임상실습 실태에 관한 연구. 한국안광학회지, 15, 319-328. 표화영(2017). 언어치료학과 대학원 석사과정의 언어재활관찰실습 현황 연구. 언어청각장애연구, 22, 421-433. 한국보건의료인국가시험원(2017). 언어재활사 직종안내. http://www.kuksiwon.or.kr/Examination/OccuLicense.aspx?PageName=LicensInfo\&Jo $\mathrm{bCode}=37 \&$ SiteGnb $=8 \&$ SiteLnb $=1$ 